\title{
Do público para o público: uma proposta de projeto-piloto para compras públicas da agricultura familiar pelo Hospital Universitário HU-UFGD
}

Caio Luis Chiariello - http://orcid.org/0000-0001-9726-5133 - caiochiariello@ufgd.edu.br ${ }^{1}$ Kamila Morandim Maidana - http://orcid.org/0000-00024642-5659-kamilamaidana@ufgd.edu.br ${ }^{1}$

Resumo - O presente artigo aborda a oportunidade de aplicação da modalidade compra institucional do Programa de Aquisição de Alimentos - PAA - no HU/UFGD. Foram analisadas as condições de demanda de alimentos pelo HU/UFGD, que se mostrou grande comprador de hortifrutigranjeiros da região. Foram analisadas também as condições de oferta de alimentos pelos agricultores familiares da região, de onde pode-se verificar que há interesse dos agricultores em vender para o HU/UFGD, sendo este um recurso que contribuirá positivamente para a melhoria de renda da população. A partir daí, foi elaborada uma proposta de melhoria que trata desde o planejamento da compra até a fase de pagamento dos agricultores. Espera-se, como alguns dos benefícios desta proposta de melhoria, entendida enquanto projeto-piloto, a adequação do órgão à legislação vigente e o fomento de uma política pública de incentivo à agricultura familiar local.

Palavras-chaves: Compras públicas; Agricultura familiar; Hospital Universitário - HU/UFGD.

\section{From public to public: a proposal for public purchase of family farmers production by the University Hospital HU-UFGD in Brazil}

\begin{abstract}
This paper highlights the opportunity to apply the institutional purchase modality of the federal Food Acquisition Program by the University Hospital - HU/UFGD. Food demand conditions by the HU/UFGD were analyzed, and the HU/UFGD proved to be a buyer of horticultural products in the region. The conditions of food supply by family farmers in the region were also analyzed, and they showed interest on selling to the HU/UFGD, and these resources may contribute to improving the local development and income. From the analyses, a propose was elaborated, that deals since the purchase planning by the HU/UFGD until the payment phase to the family farmers, making available models of public notice, sale proposal and contract. Among the benefits of this improvement proposal, the adaptation of the HU/UFGD to the current legislation and the promotion of a public policy to encourage local family farmers.
\end{abstract}

Keywords: Public purchase; Family farmers, University Hospital - HU/UFGD.

Data da Submissão: 02/09/2020

Data de aceitação: 17/04/2021

DOI: $10.51359 / 2317-0115.2021 .248159$ 


\section{Introdução}

O desenvolvimento da agricultura familiar, por muito tempo relacionado com atividades camponesas, nas últimas décadas tem recebido maior atenção, após a criação de diversos programas provenientes de políticas públicas fomentadoras da produção de pequena escala. Tais programas, explicam Junqueira e Lima (2008), buscam diminuir dificuldades costumeiras dos agricultores, como o acesso ao crédito, modernização dos equipamentos e promoção da comercialização dos produtos, de modo que, superados estes pontos, o setor possa colaborar com a economia e o desenvolvimento no local onde residem.

O Programa de Aquisição de Alimentos - PAA, exemplo de política pública de incentivo à produção da agricultura familiar por meio de compras governamentais, acrescentou, através do Decreto $n^{\circ} 7.775 / 2012$, a modalidade chamada "Compra Institucional”, possibilitando aos órgãos públicos elencados no decreto, pertencentes à União, Estados, Distrito Federal e Municípios, que anteriormente não participavam do programa, auxiliar no desenvolvimento deste segmento. O diferencial desta modalidade é que oferece aos órgãos facilidade na aquisição de alimentos por meio de dispensa de licitação, permitindo a destinação de recursos próprios do órgão para pagamento destes fornecedores, enquanto que as outras modalidades recebem recursos específicos do governo para realizar as compras. Assim, a expansão desta política pública deixa de ser totalmente dependente de recursos financeiros do Programa de Aquisição de Alimentos (PAA), utilizando a necessidade dos órgãos de adquirir alimentos como impulsionador da economia local. Tal modalidade permite ao Estado atuar não só como um agente promotor, mas também como um agente consumidor, adquirindo o que é produzido pela agricultura familiar.

Baseado na oportunidade de incentivo oferecida pela modalidade Compra Institucional, mister se faz analisar as possibilidades de sua implantação nos órgãos públicos, o que traz o seguinte questionamento, o vetor deste estudo: como uma instituição de escopo local, no caso o Hospital Universitário da Universidade Federal da Grande Dourados - U/UFGD, através de uma política pública de aquisição de alimentos, pode impulsionar as atividades da agricultura familiar na região? Como podem ser arquitetadas as compras públicas da agricultura familiar pelo HU/UFGD por meio de um projeto-piloto, alicerçado no compromisso estabelecido em lei de que o Estado fomente atividades para o desenvolvimento da agricultura familiar, contribuindo para o aumento de oportunidades para estes atores?

\section{Sobre o papel das Políticas Públicas}

O estado da arte referente ao campo das políticas públicas e seu conceito tem se transformado com o passar dos anos, muito se afastando do propósito de apenas suprir carências. A política pública de caráter social é um investimento produtivo, defende Rua (2005), devendo haver coordenação entre os objetivos desta e das políticas econômicas, uma vez que a ênfase do processo produtivo tem sido principalmente o capital humano. Ainda segundo o autor, a política pública se caracteriza como um conjunto de procedimentos destinados a promover, de maneira pacífica, a resolução de conflitos sociais. Souza (2006) destaca que a definição mais conhecida de política pública é a de Laswell, que consiste em responder às perguntas: quem ganha o quê, por quê e que diferença faz? 
Acrescenta-se a esses questionamentos, a discussão sobre o que faz as políticas públicas se enraizarem na sociedade, reforçando a distinção entre os termos "políticas de governo" e "políticas de estado". As políticas de governo são assuntos que, por influências diversas, tais como o alinhamento de lideranças, a conveniência do momento ou o clamor social, são inclusas na agenda governamental em determinado momento político, porém, não estão estruturadas de maneira que permaneçam como uma política de Estado, em forma de ato normativo ou instrumento equivalente, explica Kingdon (2003). Essas políticas de governo ao longo do tempo "esfriam" e após as mudanças dos agentes políticos, normalmente se perdem entre outros assuntos mais oportunas ao momento. Já as políticas de Estado são aquelas que, por terem sido reconhecidas como legítimas, são transformadas em leis, ou ainda são elaboradas de maneira que sua implementação ocorra, sendo incorporados às ações do Estado.

Oliveira (2011) também contribui com o entendimento deste conceito. Para o autor, as políticas de governo são formuladas e implementadas pelo Executivo e seu objetivo é responder às demandas presentes na agenda política interna, enquanto as políticas de Estado envolveriam diversas agências, além de serem submetidas, na maioria das vezes, ao Parlamento, estando disponíveis para discussão e sendo passíveis de alterações. A criação de políticas de estado que impactam significativamente na agricultura familiar possibilitou o incremento de ações de toda a Administração Pública, entretanto, o segmento ainda carece de grandes avanços e suporte técnico para dar sustentação ao desenvolvimento dos pequenos produtores, de maneira que possam continuar exercendo sua função social.

\section{Função social da Agricultura Familiar}

As expressões "agricultura familiar", "pequena produção", "produção de baixa renda", "de subsistência", "agricultura não-comercial" eram termos empregados até o final da década de 1990 (ABRAMOVAY, 2007), e desde então, revelavam o tratamento dado a esse segmento social, que era encarado como importante socialmente, mas de expressão econômica marginal. Nesse período, relata Abramovay (2007), avaliava-se que o futuro do segmento estaria comprometido pelo próprio rumo do desenvolvimento capitalista, finalmente restando apenas as lembranças do passado.

Na contramão do esperado, o panorama da agricultura familiar no Brasil, apurado pelo Censo Agropecuário, elaborado pelo Instituto Brasileiro de Geografia e Estatística (IBGE) em 2006 , permite observar que a agricultura familiar responde por $84 \%$ da produção nacional de alimentos. Ademais, a agricultura familiar e de pequena escala está vinculada à segurança alimentar mundial, pois preserva alimentos tradicionais e contribuem para uma alimentação balanceada, para a proteção da agrobiodiversidade e para o uso sustentável dos recursos naturais. Em suma, contribuem para a segurança alimentar em nível mundial, mas também local.

Entretanto, pesquisas relacionadas aos perfis de gerenciamento e planejamento estratégico retratam um segmento ávido por técnicas administrativas e com poucos recursos disponíveis para investimento. Rode (2014) realizou pesquisa de campo em 89 de 151 propriedades situadas na área do assentamento rural Lagoa Grande, na região da Grande Dourados - MS, constatando que nas propriedades com baixo nível de geração de renda, as decisões eram tomadas baseadas no curto prazo e não se adotava o controle de receitas, despesas e produtividade. Já Pádua (2014) realizou pesquisa junto a 101 produtores orgânicos de diversas regiões do estado 
do Mato Grosso do Sul, e foi possível identificar, segundo a percepção dos agricultores, que a principal dificuldade na produção é a falta de recursos financeiros para investimento, apontado por 32\% dos entrevistados. Do diagnóstico obtido neste estudo, observou-se que a maioria dos problemas apontados é decorrente de políticas públicas que não alcançam tal população. Poucas alternativas para venda, suporte na gestão e a necessidade de ampliar os canais de comercialização foram indicadas por parte dos agricultores, principalmente os que pertenciam a municípios menores

Outros autores têm direcionado seus estudos a diferentes aspectos da agricultura familiar da região: Amorim (2014), que se concentrou em redes de cooperação entre os associados, interações sociais e associativismo; Camilo (2014) buscou evidenciar e analisar a configuração socioeconômica e demográfica do assentamento Amparo, bem como a aplicação das políticas públicas neste local; Shimada (2015) avaliou qual o método de produção mais viável aos pequenos produtores da agricultura familiar, cuja pesquisa evidenciou que o método orgânico se mostra o mais adequado tanto ambiental como financeiramente, já que o preço final do produto orgânico é o principal fator limitador do consumo desses produtos.

Diante das limitações apontadas, como as dificuldades de gestão, bem como para negociar, a pequena produção demanda uma série de incentivos por meio de políticas públicas.

\section{Compra Institucional: Os Hospitais Universitários e o HU-UFGD}

A modalidade Compra Institucional, criada em 2012 pelo Decreto $\mathrm{n}^{\circ} 7.775$, objetiva a aquisição de sementes e de outros materiais propagativos provenientes da agricultura familiar, para o atendimento de demandas de consumo de alimentos, realizada por meio de chamada pública, por parte de órgãos públicos compradores. Entre os órgãos compradores, o decreto indica que tal modalidade poderá ser utilizada em instalações pertencentes a órgãos públicos de administração direta ou indireta - da União, estados, Distrito Federal ou municípios, como presídios, restaurantes universitários, academias de polícia, escolas e outros.

As compras de gêneros alimentícios no âmbito do governo federal são realizadas, via de regra, por meio de procedimento licitatório na modalidade pregão eletrônico, uma vez que, pelas suas características, se enquadram como bens comuns que podem ter seus atributos descritos nos projetos básicos que compõem o edital de convocação. Já para a compra de alimentos via Decreto 7.775/2012, o procedimento será formalizado por meio da dispensa de licitação, credenciando produtores que estiverem com a Declaração de Aptidão ao PRONAF (DAP) atualizada. Nestes casos, os valores dos alimentos serão previamente tabelados, de acordo com o valor de mercado, e os critérios de classificação levarão em conta quesitos como maior proximidade do local da plantação, integração do produtor às comunidades quilombolas, entre outros.

A modalidade compra institucional tem estimulado os governos a criarem seus próprios mecanismos de compras públicas e também as organizações da agricultura familiar a construir novos mercados, quer sejam públicos ou privados, defendem Grisa e Schneider (2015). Contribuem, assim, para a valorização da produção local/regional, ecológica/orgânica e dão um novo significado aos produtos da agricultura familiar, promovendo novos atributos de qualidade, além de justiça social, equidade, cultura e tradição. 
Esta nova modalidade amplia significativamente as oportunidades de mercado para o agricultor familiar, o que pode aumentar muito o alcance do programa (SAMBUICHI, 2014). Visando maximizar a abrangência do PAA, foi definido, como nas outras modalidades, um valor máximo de compras. Inicialmente, o valor limite era de $\mathrm{R} \$ 2,5$ mil por agricultor e por ano, mas após sofrer reajustes ao longo do tempo de existência do programa, seu limite a partir de 2017 chegou a R \$ 20 mil por ano, por agricultor.

Os hospitais universitários brasileiros, cujas atividades sejam voltadas para o tratamento da saúde dos pacientes, além de ser ambiente de ensino e pesquisa, também necessitam de atividades intermediárias que auxiliam na permanência dos pacientes, estando, entre essas atividades, o fornecimento de refeições adequadas. O modo como cada hospital adquire e produz essas refeições se diferencia, sendo discricionário ao gestor público definir a melhor forma de organização do serviço. O quadro a seguir mostra o mapeamento das aquisições:

\begin{tabular}{|c|c|c|c|}
\hline Quadro 01: Forma como os HUs adquirem alimentos, identificados por região no Brasil. \\
\hline Região & $\begin{array}{c}\text { Compra alimentos } \\
\text { Diretamente do fornece- } \\
\text { dor }\end{array}$ & $\begin{array}{c}\text { Terceiriza res- } \\
\text { taurante }\end{array}$ & Total \\
\hline Nordeste & 9 & 6 & 15 \\
\hline Norte & 2 & 1 & 3 \\
\hline Centro-oeste & 1 & 4 & 5 \\
\hline Sul & 6 & 0 & 13 \\
\hline Sudeste & 7 & 6 & 42 \\
\hline Total & 25 & 17 & \\
\hline Elaborado pelos autores & & \\
\multicolumn{4}{|l}{ Fonte: Compras Governamentais (2016). } \\
\hline
\end{tabular}

Com base em dados obtidos tanto através de contatos telefônicos quanto através de consulta ao banco de dados do sítio eletrônico Compras Governamentais dos 42 hospitais universitários examinados, verificou-se que 25 deles compravam os alimentos necessários para preparo de refeições diretamente do fornecedor, realizando licitação especificamente para fornecimento dos produtos, como pode ser observado no Quadro 01. Os demais hospitais, totalizando 17, terceirizavam a compra de alimentos por meio da contratação de empresas encarregadas de elaborar as refeições da instituição, sendo elas também responsáveis pelo fornecimento de gêneros alimentícios, incluindo carnes, grãos e hortifrutigranjeiros.

Percebe-se que a parcela de instituições que realizavam a aquisição de alimentos diretamente do fornecedor é maior do que as de que terceirizam seus restaurantes em todas as regiões, excetuando-se o Centro-oeste. Nessa região, dos 5 hospitais pesquisados, apenas o HU/UFGD realizava a compra de alimentos, sem terceirizações. No restante dos órgãos, competia à empresa terceirizada fornecedora de refeições a compra dos produtos necessários para o cardápio. Já na região Sul, nenhum hospital universitário contratava empresa terceirizada para fornecer as refeições, ficando a cargo dos hospitais a aquisição de alimentos. 
Em nenhum dos órgãos que terceirizam o serviço de fornecimento de refeições foi localizada cláusula que incentivasse a empresa prestadora de serviços a fomentar a agricultura local ou até mesmo o fornecimento de produtos orgânicos. $\mathrm{O}$ foco principal eram os deveres da contratada e condições para que se prestasse o serviço.

Como pode ser observado, embora a legislação permita que os hospitais façam dispensa de licitação para aquisição dos alimentos, nenhum dos hospitais universitários pesquisados realizou a compra utilizando este artifício legal. Além disso, quase que a totalidade dos órgãos ainda não havia se adaptado para realizar licitações exclusivas para microempresas, empresas de pequeno porte, pequenos produtos e agricultores familiares, mesmo após o Decreto 8.358/2015 ter entrado em vigência.

Nos órgãos que terceirizam as refeições, 12 celebraram contrato com sua respectiva empresa antes de 2016, ou seja, antes da vigência do Decreto 8.538/2015. Tal fato pode justificar a não existência de cláusulas de direcionamento nos seus editais. No entanto, a inadequação à legislação vigente não foi motivo para rescisão do atual contrato e abertura de nova licitação, vez que os contratos pesquisados ainda estavam vigentes na data do recorte temporal do estudo.

Pode-se concluir, a partir dos números demonstrados, que os editais de licitação dos HUs, de modo geral, não estavam adaptados à legislação vigente e também que não incentivavam diretamente o desenvolvimento das políticas públicas voltadas para a pequena produção e a agricultura familiar.

Identificadas essas características no cenário atual de compra de alimentos dos hospitais universitários, se observa que há necessidade de adequações nas aquisições dos produtos citados para que o decreto de aquisição de alimentos da agricultura familiar seja cumprido de fato. Sendo assim, realizar a aquisição de alimentos através da modalidade de compra institucional do PAA é uma forma de adequação dos órgãos à legislação vigente.

\subsection{Condições de demanda de alimentos pelo HU/UFGD}

O HU/UFGD fazia parte da maioria dos hospitais que realiza licitação especificamente para compra de alimentos ${ }^{1}$. Seu edital não restringiu a participação à apenas os licitantes mencionados no Decreto 8.538/2015.

Diante da grande variedade de dietas restritivas que o HU/UFGD precisa elaborar, a lista de insumos necessários precisa ser completa e múltipla, oferecendo todos os tipos de nutrientes para a correta alimentação das pessoas dependentes deste serviço. Estes alimentos são utilizados para compor as refeições oferecidas pelo HU/UFGD dos pacientes internados e seus colaboradores.

No que tange à montantes de recursos financeiros, a evolução no volume de compras do HU/UFGD, de 2009 a 2016, pode ser observada no Quadro 02. Ao analisar os valores das compras referentes à aquisição de hortifrutigranjeiros para o abastecimento no ano de 2016, o

1 Em 2017, por meio do pregão eletrônico nº 85/2017, o HU/UFGD terceirizou o abastecimento de alimentos para a empresa contratada e responsável por fornecer, também, a mão de obra especializada para fornecimento de refeições. 
pregão teve o valor registrado em ata totalizando $\mathrm{R} \$ 815.224,50$, somando 75 itens distribuídos entre frutas, verduras, legumes e hortaliças, além do fornecimento de ovos.

Quadro 02: Valores contratados e localidade das empresas fornecedoras do HU/UFGD.

\begin{tabular}{|c|c|c|}
\hline Ano & Valor Contratado (R\$) & Localidade da Empresa Fornecedora \\
\hline 2009 & 257.077 & Amambai - MS \\
\hline 2010 & 295.772 & Dourados - MS \\
\hline 2011 & 275.339 & Campo Grande - MS \\
\hline 2012 & 568.014 & Amambai - MS \\
\hline 2013 & 504.416 & Campo Grande - MS \\
\hline 2014 & 444.801 & Campo Grande - MS \\
\hline 2016 & 815.224 & \\
\hline Elaborado pelos autores & \\
& \multicolumn{2}{|c}{ Fonte:Compras Governamentais, 2016. } \\
\hline
\end{tabular}

Quanto ao local de estabelecimento das empresas fornecedoras, de 2009 a 2016, apenas uma das licitações foi vencida por empresa de Dourados. Os demais fornecedores do hospital são de outras cidades do estado, ou seja, os valores despendidos pelo HU/UFGD não foram direcionados para a região e, consequentemente, não se converteram em renda para a economia local.

A apresentação dos dados supracitados visa ilustrar a demanda do HU/UFGD por alimentos in natura. Além destes, outros produtos são adquiridos, entretanto, por sua especificidade, necessitam passar pelo processo de industrialização, ou seja, não são produzidos pela agricultura familiar, o que os afasta do escopo deste trabalho.

Depreende-se dos dados que o HU/UFGD é um demandante de produtos em grande volume. Para a completa identificação da existência de uma relação de comercialização, é necessário identificar as condições de oferta de alimentos pela agricultura familiar da região estudada, o que ocorrerá na seção a seguir.

\subsection{Condições de oferta pela Agricultura Familiar na região de Dourados/MS}

Existe, conforme pormenorizado, grande demanda de alimentos pelo HU/UFGD. Cabe, porém, analisar as possibilidades de oferta de alimentos na região e as peculiaridades da produção familiar para traçar uma estratégia do fornecimento de alimentos. É a partir dessas informações que se constrói um pedido de compra da instituição, considerando os alimentos que serão produzidos e a capacidade de entrega dos produtos, sua sazonalidade, entre outros fatores que merecem atenção.

$\mathrm{Na}$ tentativa de identificar como a agricultura familiar produz, na região pesquisada, foram realizados levantamentos sobre a quantidade de famílias que estariam aptas a participar da modalidade compra institucional, além de detectar se havia o interesse desses produtores em fornecer os alimentos a um novo mercado. 
Com vistas a retratar as características da produção familiar, alguns dados foram levantados junto ao Ministério do Desenvolvimento Agrário - MDA quanto ao número de produtores cadastrados no Programa Nacional de Fortalecimento da Agricultura Familiar - PRONAF em Dourados/MS. Em julho de 2016, o número de Declaração de Aptidão ao Pronaf - DAP para pessoa física (DAP-PF) era de 2.727, sendo 1.928 ativas e 745 inativas. Ou seja, do total de produtores que estavam aptos ao PRONAF, 1.928 eram atuantes. Esses dados são relevantes, pois a DAP é um dos documentos necessários para o agricultor participar das chamadas públicas da modalidade Compra Institucional.

Em relação às organizações detentoras de DAP para pessoa jurídica (DAP-PJ) no município, foram localizadas 04 associações, cujo número de associados pode ser visualizado na Tabela 01:

\begin{tabular}{|l|c|c|c|}
\hline \multicolumn{2}{|c|}{ Tabela 01: Quantidade de DAP-PJ registradas no município de Dourados/MS e seus associados. } \\
\hline Organização & $\begin{array}{c}\text { DAPs reconheci- } \\
\text { das pelo MDA }\end{array}$ & $\begin{array}{c}\text { Associados } \\
\text { sem DAP }\end{array}$ & $\begin{array}{c}\text { Total de } \\
\text { Associados }\end{array}$ \\
\hline $\begin{array}{l}\text { Associação de Produtos da Agrovila } \\
\text { Formosa }\end{array}$ & 55 & 28 & 83 \\
\hline $\begin{array}{l}\text { Centro Organizacional da Cultura } \\
\text { Tradicional da Etnia Kaiowá de } \\
\text { Dourados }\end{array}$ & 130 & 10 & 140 \\
\hline $\begin{array}{l}\text { Associação dos Agricultores da Vila } \\
\text { Vargas e Região Agrovargas }\end{array}$ & 18 & 12 & 30 \\
\hline $\begin{array}{l}\text { Associação dos Produtores de Hor- } \\
\text { tifrútis e Grãos da Grande Dourados } \\
\text { Campo Verde }\end{array}$ & 38 & 12 & 50 \\
\hline Total & 241 & 62 & 303 \\
\hline \multicolumn{4}{|c|}{$\begin{array}{c}\text { Flaborado pelos autores } \\
\text { Fonte: MDA (2016) }\end{array}$} \\
\hline
\end{tabular}

Essas associações podem ter, em sua composição, agricultores associados que não possuem a DAP-PF, de forma que eles também possam participar da modalidade Compra Institucional, na figura da pessoa jurídica "associação", fornecendo alimentos. Desse modo, é possível considerar como participantes, além dos detentores de DAP-PJ e DAP-PF, os associados sem DAP que integram as associações, totalizando um número de 1.990 produtores aptos em Dourados/MS.

É necessário mencionar a Associação dos Produtores Orgânicos de Mato Grosso do Sul APOMS, cuja sede não está localizada no município de Dourados, mas em Glória de Dourados/ MS. A associação é bastante atuante na região pesquisada e conta com 263 associados de várias cidades de Mato Grosso do Sul, sendo 214 associados com DAP-PF e 49 associados sem DAPPF. A APOMS foi indicada pela Diretora de Agricultura Familiar do município como a maior e mais atuante na região, além de ser a mais bem estruturada administrativamente. Também foi mencionada como a mais presente em diversas negociações com a prefeitura em busca de locais e estrutura para venda dos produtos pelos agricultores da região. 
Em entrevista aos presidentes de duas associações, quando questionados sobre os principais itens produzidos pelos associados, um deles elencou vários produtos e possibilitou fornecer uma lista de toda a sua produção. Já outra conseguiu citar vários produtos, mas afirmou não possuir uma relação com as quantidades totais produzidas, uma vez que a associação é nova, começando a atuar no início de 2016. Dessa forma, eles têm informações sobre a produção de alguns alimentos cuja colheita já ocorreu, mas há alguns itens que só serão comercializados no final do ano, quando aptos para serem colhidos e vendidos.

Com relação aos principais canais de venda dos produtos, os representantes afirmaram comercializar seus produtos principalmente nas feiras de produtores da região, contando que os produtos mais "bonitos" (produtos maiores) normalmente são separados para serem vendidos a granel nas feiras, já que os consumidores são mais exigentes e apreciam os produtos mais vistosos. Assim, as alfaces, por exemplo, são vendidas por unidade. Já os produtos menores, que embora tenham sido plantados da mesma maneira, tenham se desenvolvido menos, são separados e comercializados na CONAB, onde as alfaces são vendidas por quilograma, ou seja, o seu tamanho é irrelevante, revela o entrevistado. Essa metodologia da CONAB, para parte do grupo, não é ideal, pois muitos produtos, principalmente as hortaliças, são produzidas por unidade. $\mathrm{O}$ valor do quilograma também não é o ideal, continua o agricultor, pois o preço do quilo é um pouco baixo.

Como pode ser extraído da fala do agricultor, a CONAB é a alternativa que eles possuem para vender o excedente de produção que não é adquirido nas feiras. Dessa forma, embora o valor não seja considerado justo pelo produto, os agricultores optam por vender à CONAB para não perder o que foi produzido.

O outro entrevistado relata que sua associação não tem mais vendido para a CONAB, e que vem buscando novos meios para comercializar. Um exemplo dado é a intenção da associação em criar uma página na internet para que os compradores possam fazer seus pedidos on-line e programar as entregas dos produtos em suas próprias casas. Foi relatado também que, para operacionalizar o website, foi buscado o auxílio da UFGD, de modo que houvesse um apoio técnico. Ainda na UFGD, foi disponibilizado um espaço para que os associados pudessem comercializar seus produtos todos os dias, na cidade universitária. Outro projeto, até então em andamento, é a construção de um Centro de Comercialização da própria associação, que contou com financiamento obtido junto a uma entidade bancária.

A partir desses primeiros relatos, é possível observar a intenção das associações em buscar novos mercados. Os associados têm utilizado medidas criativas para tentar se adaptar às dificuldades que limitam possíveis compradores a obterem os produtos, como falta de tempo para irem até as feiras.

Quando questionados se eles possuíam contratos com outros órgãos por meio do PAA e do Programa Nacional de Alimentação Escolar - PNAE, uma das associações afirmou que não possuía, somente participava do Programa Mesa Brasil. A outra associação afirmou que possuía alguns contratos do PNAE e que estava divulgando o PAA em vários órgãos para incentivar as chamadas públicas.

Questionados se eles teriam interesse na Compra Institucional do PAA pelo HU/UFGD, os representantes das associações se manifestaram favoráveis à chamada pública. Um dos entrevistados disse ter almejado participar da chamada pública do Exército local, mas, no dia, se 
atrasou e só pôde assistir à sessão pública.

Dificuldades administrativas foram apontadas por ambas as associações. O entrevistado expôs que o atraso para chegar na chamada pública do Exército foi ocasionado pela dificuldade em controlar o vencimento da DAP dos associados. No dia agendado para a aquisição do Exército, relata, ao conferir os documentos dos associados que seriam responsáveis pelo fornecimento dos alimentos, duas DAP-PF estavam vencidas. Em decorrência do vencimento das DAPs, foi necessário redistribuir os itens entre os associados, respeitando produção, disponibilidade e limite de valores de cada agricultor, estipulado na modalidade Compra Institucional. O entrevistado não atribui somente a isso o atraso na chamada pública, entretanto, ponderou que essas dificuldades administrativas atrapalharam bastante.

Quanto à outra associação, a data em que se realizou a entrevista foi anterior à chamada pública. Entretanto, é do conhecimento da pesquisadora, por meio da conversa realizada com o Exército local que a associação não participou da chamada.

Embora não haja justificativa para a ausência na chamada pública, o agricultor relatou durante a entrevista que a associação estava apresentando dificuldades para emissão de notas fiscais. As dificuldades se tratavam de questões administrativas com relação à criação da associação, documentos a serem gerados e licenças que eram necessárias. As limitações normalmente são decorrentes da falta de conhecimento dos associados, como ele descreveu.

Por fim, ao questionar se as associações seriam capazes de assumir compromissos de fornecimento com o HU/UFGD, ambos os entrevistados demonstraram interesse. Um deles relata que os agricultores têm capacidade para produzir mais, mas não arriscam aumentar a produção sem ter a venda certa. Eles só vão aumentar a produção quando tiverem a garantia que irão vender .Nas palavras do entrevistado, a compra institucional "é um recurso e ele [o agricultor] tem que entender que é um valor interessante e é uma garantia”.

A partir dos relatos obtidos, alguns pontos se destacam, como, por exemplo, o interesse das associações em comercializar com o HU/UFGD e a dificuldade administrativa que elas apresentam decorrente da falta de apoio técnico. Nesse sentido, as respostas recebidas corroboram com a perspectiva de adesão dos atores da agricultura familiar da região de Dourados-MS, enquanto provedores de parte da demanda de alimentos do HU/UFGD. Fica claro, também, que o órgão necessitará dispender apoio aos agricultores, visando obter sucesso na chamada pública.

\section{Discussões e proposta de melhoria}

Apesar dos esforços, como relata Dias (2013), a comercialização ainda é o fator de maior fragilidade para os agricultores familiares, que muitas vezes se tornam vulneráveis à ação dos chamados 'atravessadores' ou intermediários, que compram os seus excedentes de produção agrícola. No mesmo sentido, Silva, Grossi e França (2010) comentam que muitos agricultores familiares, normalmente os mais pobres, não têm incentivos para ampliar sua produção, pois não conseguem comercializar seus produtos a preços compatíveis com seus custos, especialmente porque ficavam reféns dos atravessadores. Assim, quanto maior é a dificuldade para vender os produtos e gerar renda, menos restam alimentos para o autoconsumo. Concluem os autores que, onde reinam as regras do livre mercado, com a concentração da propriedade 
e mercados imperfeitos ou inexistentes, ocorre a marginalização de empreendimentos. Estes, muitas vezes expostos a uma competição não mediada com produtos gerados em larga escala, colocam milhares de agricultores em situação de difícil competitividade.

A priori, na tentativa de modificar esse cenário, a modalidade compra institucional do PAA fornece meios para que o HU/UFGD possa cooperar com essa política pública. A agricultura familiar representa uma oportunidade para que a instituição contribua com a economia local. A aquisição de alimentos, aliada aos mecanismos da política pública voltada para esta população, pode colaborar destinando mais recursos para os produtores de Dourados/MS e região, de modo que essa ação promova a proteção social e o bem-estar da comunidade.

\subsection{Roteiro para o plano de ação na elaboração de um projeto-piloto}

Demonstrada a oportunidade de comercialização de alimentos produzidos pela agricultura familiar, cabe ao HU/UFGD dar início à chamada pública. Para tanto, alguns pontos precisam ser observados para estabelecer a relação comercial entre os atores envolvidos. Para compreensão do roteiro a ser seguido, a Figura 01 demonstra todas as etapas do plano de ação.

Figura 01:Fluxograma do roteiro de para Compra Institucional no HU/UFGD.

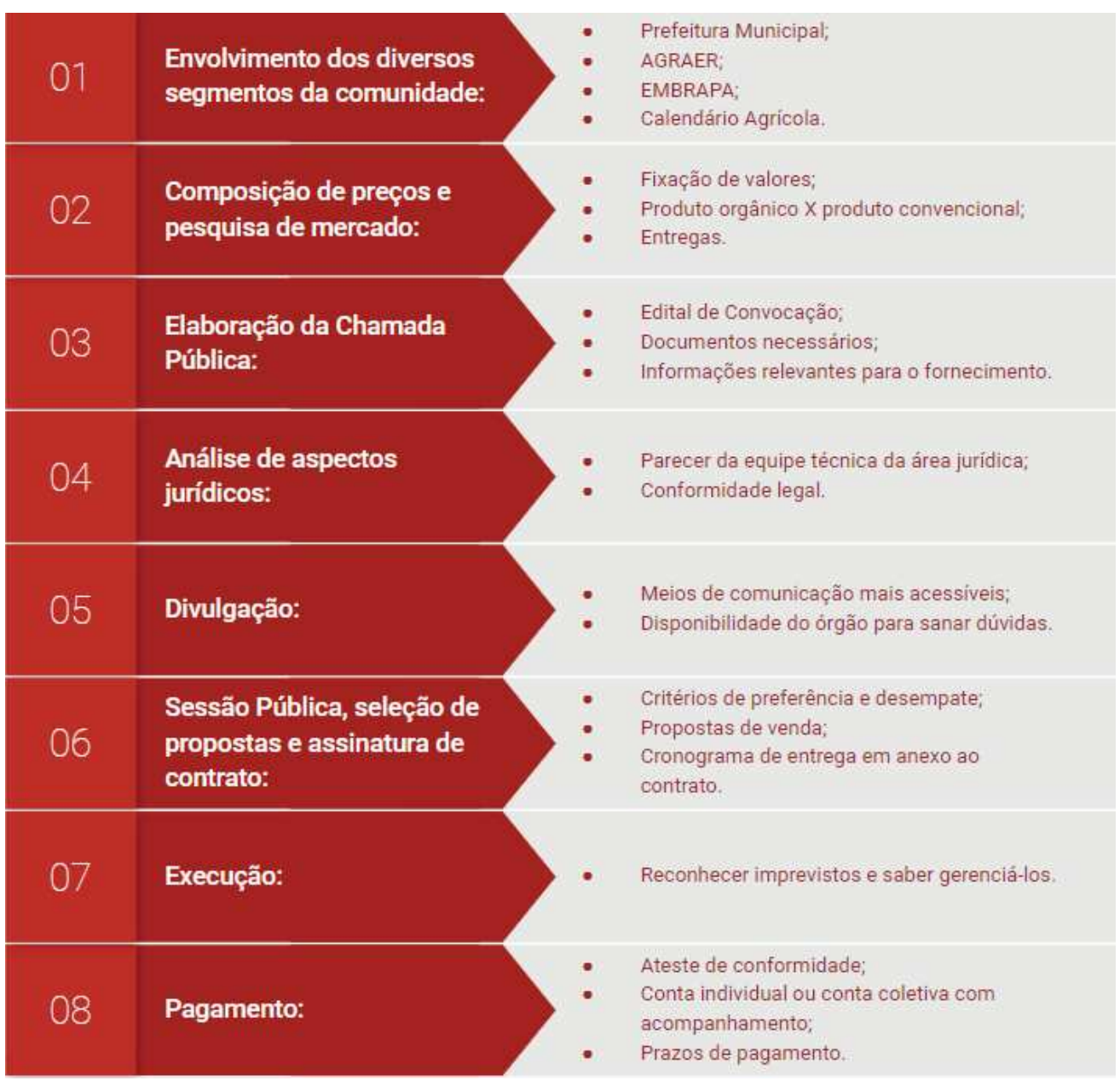

Elaborado pelos autores 


\subsubsection{Envolvimento dos diversos segmentos da comunidade}

A articulação entre os membros da sociedade no desenvolvimento da chamada pública de aquisição de alimentos trata-se de importante parte da estratégia para alcançar o sucesso da compra. É preciso estabelecer o diálogo entre os vários componentes da comunidade, visando obter parcerias e apoio operacional. $\mathrm{O}$ trabalho em conjunto facilita o acesso à informação de qualidade, orientando os procedimentos aos interessados ou, ainda, encaminhando os agricultores para os atores corretos. Essa articulação favorece o entendimento e correto direcionamento, evitando retrabalhos e perda de tempo, o que pode desestimular os pequenos produtores a participarem da chamada pública devido ao pouco conhecimento e acesso.

A articulação entre os atores locais envolve o trabalho em conjunto para desenvolver o mapeamento dos produtos e suas respectivas épocas de colheita, construindo um calendário agrícola da região. Esse tipo de calendário auxiliaria os nutricionistas do HU/UFGD na construção do cardápio, que precisa ser preparado de acordo com a restrição alimentar de cada paciente. Outro benefício do calendário agrícola é possibilitar a previsão de variações no fornecimento dos alimentos, o que foi apontado pelos agricultores como uma das principais dificuldades para manter um contrato de quantidades significativas. Com o calendário, é possível que haja o planejamento de acordo com a sazonalidade dos produtos. Condições como o clima, solo, instalações dos produtores são algumas informações fundamentais para diminuir os riscos de gargalos na produção, comprometendo a entrega de alimentos.

\subsubsection{Composição dos preços e pesquisa de mercado}

Os preços dos produtos são indicados pelos agricultores como o principal entrave para a comercialização (BEZERRA, 2015). Dessa maneira, para que os preços sejam os mais parecidos com os custos reais, gastos com frete, embalagens, impostos, ou seja, todas as despesas necessárias para produção e comercialização devem ser consideradas para formação dos preços devendo ser apresentadas na Chamada Pública. A periodicidade de entrega dos alimentos é importante para definir os custos com o transporte dos alimentos.

Uma prática encontrada nas cartilhas de orientação do PNAE para solucionar problemas de logística é o órgão comprador se responsabilizar pela coleta e distribuição dos alimentos nas escolas. Assim, se o órgão optar por buscar os alimentos, serão considerados como frete apenas os custos para a entrega nas centrais de distribuição.

O essencial é que as condições de fornecimento estejam claramente definidas no edital da Chamada Pública, evitando distorções nos valores de referência. Os preços, neste caso, não serão critério de classificação, como ocorre normalmente nos processos licitatórios. Portanto, o preço final deve ser o mais real possível, uma vez que não haverá ajustes durante a Chamada Pública.

As Centrais Estaduais de Abastecimento Sociedade Anônima (CEASA) podem ser fontes de valores e, em alguns estados, disponibilizam eletronicamente relatórios com os preços diários e/ou semanais. O art. 5º parágrafo segundo, da Resolução GGPAA n ${ }^{\circ}$ 50/2012 faculta ao órgão responsável pela compra a utilização dos preços de referência estabelecidos nas aquisições do Programa Nacional de Alimentação Escolar - PNAE. 
Para produtos orgânicos ou agroecológicos, a Compra Institucional prevê a possibilidade de pagamento de valores diferenciados. Se não for possível obter no mínimo três valores para definir o preço dos produtos, há previsão legal de ser adicionado $30 \%$ ao preço normal para determinar o valor do produto (art.17, parágrafo único, da Lei $n^{0} 12.512$, de 2011).

\subsubsection{Elaboração da chamada pública}

Com o levantamento das quantidades a serem adquiridas, as condições de entrega e os preços dos produtos, é possível elaborar o edital da Chamada Pública. O edital de convocação deverá ser um documento simples, de fácil leitura e interpretação. Nele, devem conter endereços de entrega, prazos, condições de recebimento dos produtos e documentos necessários para a participação dos agricultores.

4.1.4 Análise dos aspectos jurídicos inerentes à Chamada Pública

Em consonância com a legislação vigente, ainda na fase preparatória da Chamada Pública, a área jurídica da instituição deverá emitir parecer, conforme preconiza o artigo 28 , inciso VI da Lei $n^{\circ}$ 8.666, de 1993. Tal parecer deverá apreciar a instrução e cabimento legal das etapas do processo, sob pena de tornar os atos nulos.

\subsubsection{Divulgação da chamada pública e elaboração das propostas de venda}

A ampla divulgação da Chamada Pública é fundamental para o conhecimento dos interessados em fornecer os alimentos. Deve ser realizada na maior variedade de meios de comunicação possíveis, principalmente no rádio e na televisão local, uma vez que estes foram evidenciados pelo estudo de Bezerra (2015) como os meios mais comuns de acesso à informação pelos agricultores familiares.

Com o apoio das entidades parceiras, a divulgação pode ocorrer também por meio de panfletos e folders explicativos, disponíveis em locais de grande circulação dos produtores, como em feiras, na CONAB, prefeitura, universidades, além de páginas eletrônicas nas redes sociais. Ademais, investir na divulgação em rádios e canais de televisão locais alcança uma fatia considerável da população rural quando comparado à internet e jornais, como constatado no estudo de Bezerra (2015).

Após a divulgação da Chamada Pública, os interessados em participar poderão elaborar sua proposta de venda, relacionando os produtos que fornecerão. Esse documento é importante para definir quais produtos, pesos e valores serão destinados a cada agricultor, de maneira que não ultrapasse os limites estabelecidos pelo PAA. Embora seja um documento simples, o órgão precisa estar preparado para auxiliar os agricultores no preenchimento da proposta.

Por tratar-se de uma nova forma de aquisição, os produtores podem ter dúvidas ou ainda se sentirem inseguros e precisarem de apoio. O órgão precisará estar disponível para receber 
esse tipo de procura e seria de grande importância deixar essa informação clara na divulgação da chamada pública, possibilitando uma abertura ao agricultor que tiver dúvidas quanto ao fornecimento e demais assuntos.

\subsubsection{Sessão pública, seleção das propostas e assinatura de contrato}

$\mathrm{Na}$ data agendada, os documentos serão recebidos pelo órgão, que fará a análise das propostas de venda respeitando os critérios de preferência estabelecidos na Resolução GGPAA $\mathrm{n}^{\circ}$ 50/2012, na seguinte ordem: 1) agricultores familiares do município; 2) comunidades tradicionais, quilombolas ou indígenas; 3 ) assentamentos da reforma agrária; 4) grupos de mulheres; e 5) produção agroecológica ou orgânica.

Os critérios de preferência e desempate devem sempre estar claramente dispostos ao longo do edital, bem como todas as condutas durante a sessão pública. $\mathrm{O}$ andamento da Chamada Pública deverá ser registrado em ata, assinada pelos participantes.

Depois de encerrada a Chamada Pública, órgão e fornecedores poderão assinar os contratos, que deverão conter cronograma de entrega dos produtos, prazos de pagamento e condições que haviam sido previamente estabelecidas no edital de convocação.

A formalização do contrato significa assumir o compromisso de fornecimento pelo período indicado, portanto, o fornecedor deve entender a importância do instrumento. O cronograma de entrega dos produtos deve acompanhar o contrato, respeitando também o que consta na proposta de venda do produtor.

\subsubsection{Execução}

Encerradas as etapas de planejamento e formalização das compras, inicia-se a fase da execução do contrato. $\mathrm{O}$ fornecedor deverá respeitar os prazos fixados e as quantidades definidas para entrega.

Essa fase tende a ser a de maior complexidade, pois se refere à comercialização, de fato. As etapas iniciais, embora de imensa importância, tratavam-se de planejamento e negociação. Nesta etapa, o agricultor deverá entregar o que foi contratado e poderá se deparar com dificuldades não previstas anteriormente.

Mudanças inesperadas nas condições climáticas são a principal interferência que pode afetar a execução do contrato, como relatado pelos agricultores. Manter uma produção constante, estando sujeito às alterações que não podem ser controladas, será a maior dificuldade a ser enfrentada pelos agricultores familiares. Sobre este ponto, o mais provável é que as associações sejam mais resistentes, diante destas dificuldades, que os produtores individuais.

Desse modo, o órgão precisa ficar atento aos diversos fatores que atingem a produção dos agricultores, sempre lembrando que a estrutura para a produção é pequena. Ser razoável diante de eventualidades imprevisíveis pode garantir o sucesso da transação comercial. 
Sempre que ocorrer a entrega dos produtos, deverá ser assinado o termo de recebimento dos alimentos, em duas vias, uma para o pagamento pelo órgão e outro para controle do agricultor.

\subsubsection{Pagamento}

O processo de compra será concluído quando for realizado o pagamento pelos alimentos recebidos aos agricultores. Após o recebimento dos produtos e ateste de conformidade pelo servidor responsável, a nota fiscal ou o termo de recebimento de cada agricultor poderá ser encaminhado ao setor financeiro, que realizará o pagamento de acordo com o modelo de organização dos agricultores. Se na chamada pública eles se apresentaram como grupos informais ou agricultores individuais, o pagamento será realizado diretamente na conta bancária de cada fornecedor. Caso eles tenham participado como grupo formal, o pagamento será realizado na conta bancária do grupo. Essa conta deverá ser aberta para fins de recebimento destes valores e, ao final de cada período, o grupo formal deverá informar os comprovantes de pagamento de valores aos respectivos agricultores beneficiários. A legislação do PAA ainda prevê que a conta bancária aberta deverá permitir o acompanhamento da sua movimentação pela unidade gestora.

Embora a legislação não seja taxativa quanto ao prazo de pagamento das notas fiscais, o órgão deverá sempre realizar os pagamentos de maneira mais breve possível. O edital da chamada pública conterá informações quanto aos prazos e a instituição não poderá negligenciá-los. Empresas formais costumam possuir um capital de giro que permite pequenos atrasos em pagamentos, não comprometendo sua saúde financeira, entretanto, a compra da agricultura familiar tratada neste estudo refere-se a valores que representarão parcelas da renda mensal dos pequenos produtores.

Para o órgão, toda a realização do projeto, a definição dos itens a serem comprados, a elaboração da chamada pública, enfim, todos os procedimentos necessários fazem parte de um grande e importante conjunto. Para os agricultores, a etapa do pagamento é a principal fase, uma vez que todo o esforço é dispendido visando a remuneração pelos seus trabalhos. É também a conclusão da primeira etapa de um ciclo que beneficiará essa população.

\subsection{Benefícios e limitações da alternativa indicada}

O conjunto de ações proposto neste estudo é voltado para a transformação da realidade, diante da oportunidade de melhoria vislumbrada. Com a adoção da modalidade compra institucional, esperam-se benefícios para ambos os componentes da relação comercial: órgão e agricultor.

Um dos avanços esperados pela aplicação do projeto-piloto é a participação do HU/ UFGD na melhoria de condições materiais de vida dos agricultores familiares da região. Isso se deve à conversão de parte do orçamento do órgão diretamente aos pequenos produtores, sem a figura de intermediários. A demanda de alimentos representa também a geração de empregos no campo, oferecendo os recursos necessários para que os agricultores não necessitem de outras fontes de renda. O estudo de Bezerra (2015) revelou que os agricultores que se dedicavam exclusivamente à atividade do campo possuíam remuneração total mensal superior aos que tinham 
outras ocupações para complementar a renda. Assim, a aquisição de alimentos pelo HU/UFGD pode representar, além do aumento de remuneração, a garantia da realização da venda pelos produtores, favorecendo a permanência das famílias no campo.

O rol de alimentos a serem adquiridos permite que a compra institucional seja uma oportunidade para muitos agricultores familiares, independentemente de sua produção. Pode alcançar várias famílias, uma vez que o HU/UFGD compra em grande quantidade e em boa variedade, dando chance para todo tipo de alimento participar. Aliada ao propósito de incentivar a produção familiar, a aquisição e o consumo de produtos provenientes da agricultura local irão permitir o fornecimento de alimentos mais frescos, uma vez que não precisam ser transportados de outros municípios, diminuindo o tempo entre a colheita e a utilização e proporcionando maior qualidade nutricional aos consumidores de refeições do órgão.

A oportunidade da compra institucional trata-se de um desafio para a agricultura familiar: se desenvolver e conseguir acessar novos mercados, principalmente para a gestão das associações. Entretanto, chances devem ser dadas a essa população para que modifiquem o status quo.

Para as associações mais novas, há a limitação de assumir um compromisso, pois a produção ainda é variável, ou seja, o critério da confiabilidade é posto em xeque. Assim, as associações mais antigas e que possuem registro do que é produzido podem estar mais perto de assumir um compromisso com o HU/UFGD. Esse pode ser um dos fatores que influenciam na decisão dos agricultores individuais ao assumirem um compromisso de fornecimento, já que a variação da produção é um risco existente e muitas vezes imprevisível.

Ao questionar um agricultor se este gostaria de vender seus alimentos ao HU/UFGD, é de certo modo óbvio que a resposta obtida seria afirmativa, como a maioria dos comerciantes responderiam. Entretanto, em um segundo momento, após analisadas as condições de fornecimento, periodicidade etc., é natural que alguns deles percam o interesse, ponderando quanto ao lucro que obteriam e a responsabilidade que envolveria o compromisso de um contrato. É possível também que estes sejam influenciados pelo pouco conhecimento sobre o tema.

Esses fatores comportamentais devem ser considerados pelo administrador público para que este não se frustre nas primeiras chamadas públicas. Se a expectativa de sucesso não for atendida nas primeiras tentativas de contratação, é relevante que o órgão não desista de continuar tentando contratar com a agricultura familiar. Isso porque, para o agricultor, ser um dos responsáveis pela entrega de alimentos ao maior hospital público da região pode ser, de certo modo, intimidador. Essa barreira só será ultrapassada com o tempo e as parcerias estabelecidas, além do aumento da visibilidade do HU/UFGD como sendo um mercado viável e acessível.

Deve-se considerar também que a Compra Institucional é uma inovação para a Administração Pública. Assim, a existência de dúvidas, tanto no planejamento quanto na execução do projeto-piloto serão consequência do, até então, novo modelo de aquisição de alimentos.

O PAA é uma política pública que incentiva a permanência do produtor no campo, entretanto, a capacitação é de grande relevância, principalmente objetivando preparar essa população para fornecer utilizando as melhores práticas e otimizando seus recursos. É preciso capacitar os produtores para aumentar sua competitividade e essa capacitação não envolve apenas questões 
de produção, mas elementos técnicos gerenciais e de negociação. Ao estabelecer parcerias e aumentar a participação nos mercados institucionais, esses produtores estarão mais envolvidos com normas, regras, prazos, legislações, etc.

Ainda quanto à capacitação, ambos os lados da relação comercial devem estar preparados, portanto, há a necessidade de capacitar os agentes públicos para realizar as chamadas e aplicarem a legislação de maneira correta. Além de atender à legislação, é preciso conscientizar o gestor público quanto ao seu papel que, no caso do HU/UFGD, vai muito além de atender ao usuário do SUS e abrigar as atividades universitárias de ensino. Trata-se de atuar como um agente fomentador de uma política pública, por meio de um mecanismo novo e promissor. A legislação prevê a reserva de $30 \%$ dos recursos para a agricultura familiar, mas nada impede que o percentual seja maior, sendo discricionário ao órgão optar por este aumento.

Como benefício, há também a melhoria na imagem da organização e sua participação como componente ativo da sociedade, contribuindo para a melhoria das famílias locais, agindo não só como um agente de saúde, mas como um consumidor que valoriza a região. Por fim, e não menos importante, adequa o órgão à legislação vigente no país.

\section{Conclusão}

Como pode ser observado neste estudo junto aos HUs brasileiros, pouco mais da metade efetua compras de alimentos para as refeições. Em $40 \%$ dos órgãos pesquisados, que não fazem as compras diretas de alimentos, mas terceirizam os restaurantes, há a momentânea impossibilidade de aplicar a modalidade Compra Institucional. Entretanto, a impossibilidade de utilizar a modalidade não é fator limitante para a aquisição de alimentos da agricultura familiar, nem exclui o órgão da obrigação de comprar produtos dessa população. Há a possibilidade de exigir, nos contratos com as empresas responsáveis pelos restaurantes/refeitórios, que estas providenciem a compra dos alimentos diretamente de associações ou ainda dos agricultores individuais. A comprovação da compra pode ser realizada mediante comprovante de venda, fornecido pelo agricultor.

É necessário compreender que a modalidade da Compra Institucional é apresentada neste estudo como um instrumento para efetivação de uma política pública para segmentos que necessitam de suporte do Estado, e aqui nos debruçamos sobre as colocações de Sambuichi (2014, pp.99-100):

\footnotetext{
Se, por um lado, esses programas mostraram as fragilidades das políticas agrícolas e agrárias no Brasil, por outro, comprovaram que a agricultura familiar, desde que apoiada por políticas públicas adequadas, é capaz de fornecer alimentos e pode também se tornar o grande fornecedor de alimentos diversificados para garantir a segurança alimentar. Além disto, são políticas mais justas socialmente, pois, em lugar de comprar mil itens de um produtor e/ ou fornecedor, compra-se de mil produtores e tem-se o potencial de recriar mercados locais e estimular a produção.
}

Porém, os agentes públicos precisam se adaptar e buscar os instrumentos mais adequados para cada situação, desde que atinjam o objetivo esperado, que é reservar parte das aquisições de alimentos para a agricultura local. Ademais, a legislação já se encontra vigente, sendo que os pontos levantados devem ser tratados como prioridade. 
Equilibrando a balança, nada impede que o órgão mantenha sua compra costumeira via pregão eletrônico, como se mostrou a grande realidade. Não trata-se de optar por um ou outro caminho, mas de medidas graduais de adaptação tanto da rotina do órgão como da perspectiva e capacidade de fornecimento dos agricultores.

Desse modo, caso o HU/UFGD opte por alterar seu formato de compra/contratação, a legislação vigente não poderá ser ignorada e serão necessários novos estudos para incluir na contratação a reserva de recursos visando viabilizar a compra direto do agricultor familiar.

Estabelecer negociações visando a flexibilidade, formar relações de confiança, acabar com a desvantagem existente proveniente da pequena produção e criar uma cultura de cooperação são importantes barreiras a serem vencidas. Para tanto, deve haver um sincronismo entre vários agentes públicos envolvidos, uma vez que a venda a um órgão público não envolve apenas vendedor e comprador, mas vários atores da sociedade.

\section{Referências}

ABRAMOVAY, Ricardo. Paradigmas do capitalismo agrário em questão. 3. ed. São Paulo: Edusp, 2007. 296 p.

AMORIM, Robsom Marques de. Redes de cooperação em associações de pequenos produtores: um estudo no assentamento municipal Agrovila "Vila Formosa" em Dourados-MS. 2014. 79 f. Dissertação (Mestrado) - Curso de Programa de Pós-graduação em Agronegócios, Universidade Federal da Grande Dourados, Dourados, 2014.

BEZERRA, Gleicy Jardi. Agricultura familiar tradicional em Dourados/MS: limites e possibilidades para o desenvolvimento das propriedades e a geração de renda. $2016.96 \mathrm{f}$. Dissertação (Mestrado) - Curso de Programa de Pós-graduação em Agronegócios, Universidade Federal da Grande Dourados, Dourados, 2015.

CAMILO, Leandro Rennê. Assentamento Amparo no município de Dourados em Mato Grosso do Sul: caracterização e utilização de políticas de créditos. 2014 . 87 f. Dissertação (Mestrado) - Curso de Programa de Pós-graduação em Agronegócios, Universidade Federal da Grande Dourados, Dourados, 2014.

CAPELLA, A. C. N. Perspectivas teóricas sobre o processo de formulação de políticas públicas. In: HOCHMAN, G. et al. (Org.). Políticas públicas no Brasil. Rio de Janeiro: Fiocruz, p. 87121,2007

DIAS, Thiago Ferreira et al. O Programa de Aquisição de Alimentos da Agricultura Familiar (PAA) como estratégia de inserção socioeconômica: o caso do Território da Cidadania Sertão do Apodi (RN). Revista Brasileira de Gestão e Desenvolvimento Regional, Taubaté, v. 9, n. 3 , p.100-129, set. 2013.

GRISA, Catia; SCHNEIDER, Sergio. Três gerações de políticas públicas para a agricultura 
familiar e formas de interação entre sociedade e estado no Brasil. Revista de Economia e Sociologia Rural, Piracicaba - SP, v. 52, n. 1, p.125-146, fev. 2015. Disponível em: <http://www. scielo.br/pdf/resr/v52s1/a07v52s1.pdf>. Acesso em: 08 abr. 2016.

JUNQUEIRA, Clarissa Pereira; LIMA, Jandir Ferrera de. Políticas públicas para a agricultura familiar no Brasil. Semina: Ciências Sociais e Humanas, Londrina, v. 29, n. 2, p.159-176, Não é um mês valido! 2008. Disponível em: < http://www.uel.br/revistas/uel/index.php/seminasoc/ article/download/5469/4991>. Acesso em: 30 mar. 2016.

KINGDON, John W. Agendas, alternatives, and public policies. 3. ed. Nova York: Harper Collins, 2003

OLIVEIRA, Dalila Andrade. Das políticas de governo à política de estado: reflexões sobre a atual agenda educacional Brasileira. Educação \& Sociedade, Campinas, v. 32, n. 115, p.323337, abr. 2011.

PADUA, Juliana Benites. Produção e comercialização de produtos orgânicos pela agricultura familiar em Mato Grosso do Sul. 2014. 82 f. Dissertação (Mestrado) - Curso de Programa de Pós-graduação em Agronegócios, Universidade Federal da Grande Dourados, Dourados, 2014.

RODE, Manfredo. A gestão da propriedade rural: um estudo de caso a partir da realidade do assentamento Lagoa Grande, em Dourados-Mato Grosso do Sul. 2014 . 79 f. Dissertação (Mestrado) - Curso de Programa de Pós-graduação em Agronegócios, Universidade Federal da Grande Dourados, Dourados, 2014.

RUA, Maria das Graças. Políticas Públicas. Brasília, DF: Capes, UAB, 2009.

SAMBUICHI, Regina Helena Rosa et al. Compras públicas sustentáveis e agricultura familiar: a experiência do Programa De Aquisição De Alimentos (PAA) e do Programa Nacional De Alimentação Escolar (PNAE). In: SAMBUICHI, Regina Helena Rosa et al (Org.). Políticas Agroambientais e Sustentabilidade: Desafios, Oportunidades e Lições Aprendidas. Brasília: Ipea, 2014. Cap. 3. p. 75-104.

SILVA, José Graziano da; GROSSI, Mauro Eduardo del; FRANÇA, Caio Galvão de (Org.). Fome Zero: A experiência brasileira. Brasília: Mda, 2010. 360 p

SOUZA, Celina. Políticas Públicas: uma revisão da literatura. Sociologias. Porto Alegre, ano 8, n. 16, jul-dez 2006, p. 20-45. 